\title{
REVIEW \\ Yield Response of Upland NERICAs under Rain-fed Upland Conditions with Different Levels of Nitrogen Application
}

\author{
Maya MATSUNAMI and Makie KOKUBUN* \\ Graduate School of Agricultural Science, Tohoku University (Sendai, Miyagi 981-8555, Japan)
}

\begin{abstract}
NERICAs (New Rice for Africa), new genotypes produced from the interspecific hybridization of Oryza sativa and $O$. glaberrima, have been bred in an attempt to improve the yield potential of rice cultivars adapted to resource-limited conditions in Africa. Identification of physiological traits responsible for their high-yielding potential under such conditions should be useful for rice-breeding programs to be employed not only in Africa but in other regions where rice production is being undertaken under low input conditions. In a series of experiments, we evaluated the growth and yield performance of upland NERICAs under rain-fed upland conditions with two levels of nitrogen application in comparison with Japanese elite rice cultivars, and attempted to identify the physiological traits responsible for the superior yield, if any. The upland NERICAs (NERICA 1 and NERICA 5) exhibited greater biomass production and yield than Japanese cultivars. The NERICAs also showed a higher rate of transpiration and exudation during the ripening stage, compared with elite Japanese cultivars. These results suggested that the greater water uptake ability of NERICAs appeared to be associated with their high $\mathrm{N}$ uptake capability, leading to greater biomass production and yield under water- and N-limited ecosystems. Further studies are needed to identify the specific root morphology involved in the water uptake ability of NERICAs.
\end{abstract}

Discipline: Crop production

Additional key words: exudation, $\mathrm{N}$ uptake, transpiration

\section{Introduction}

In May 2008, the fourth Tokyo International Conference for African Development (TICAD IV) was held in Yokohama, Japan. To support the development of African countries, many strategies in several sectors such as the economy, environmental preservation, and education were discussed ${ }^{17}$. With regard to food production, the following specific aim was proposed: double production in Africa within the next 10 years. How do we double the production in the short term? Several approaches are being considered: to maintain the agricultural infrastructure, to fortify the education of extension workers, to improve marketing, and so forth. Of these, NERICA (New Rice for Africa) attracted attention because it has the potential to improve rice productivity through breeding new cultivars.

Rice ecosystems in West Africa are classified into upland, rain-fed lowland, irrigated lowland, mangrove swamp, deep water, and floating ecosystems ${ }^{25}$. The upland ecosystem occupies $40 \%$ of the total rice ecosystem area, but its productivity is very low (around one $t / h a$ ) because of drought, soil acidity, weeds, and N-deficien$\mathrm{cy}^{25}$. NERICAs are the interspecific progenies of Oryza sativa and $O$. glaberrima, which have been bred by the Africa Rice Center (formerly West Africa Rice Development Association (WARDA)). The conception of breeding NERICA was to combine the best traits of the two species: the stress tolerance of $O$. glaberrima and the high-yielding ability of $O$. sativa. Until now, three types of NERICA have been bred for target ecosystems: upland, irrigated lowland, and rain-fed lowland ${ }^{5}$. At the beginning of the NERICA project, research was conducted to achieve more yield by new cultivars under input-limited, weed- and drought-prone production systems ${ }^{10,11}$. Currently, 18 upland NERICA cultivars and 60 lowland NERICA cultivars have been bred, and they have started

*Corresponding author: e-mail kokubun@bios.tohoku.ac.jp

Received 2 July 2010; accepted 22 December 2010. 
to be cultivated in western and central African countries $^{1,2}$.

In the last century, rice breeding succeeded in drastically improving yield, but the high-yielding cultivars were highly dependent on irrigation and fertilization. Undoubtedly both greatly contributed to the stable high yield; however, it is estimated that irrigation might be restricted in the future, because of climate change and competition from industrial and urban use ${ }^{3}$. Since excess nitrogen fertilization can cause environmental pollution, it is necessary to develop a new and improved production system and/or cultivars that can reduce the amount of chemical fertilizer required for sustainable rice production. NERICAs, which are employed by farmers, are the first example of success in interspecific hybridization in rice. Characterization of the eco-physiological traits of NERICAs, which might have inherited tolerance to biotic/abiotic stresses from their African ancestors, should be useful to identify the traits adaptable to limited irrigation and fertilization conditions not only in Africa but also in other regions.

The upland rice-cultivation area is fairly small compared with that of lowland rice: $7 \%$ of total rice grown area in $\mathrm{Asia}^{13}$ and $0.2 \%$ in $\operatorname{Japan}^{16}$. However, upland rice plays an important role in crop rotation because it can alleviate damage caused by continuous cropping ${ }^{8}$. In addition, it is estimated that 15-20 million ha of irrigated rice ecosystems are likely to suffer from water scarcity by $2025^{26}$, so there is a growing need for the improvement of upland rice yield. Since rice is very sensitive to water shortages, the genetic improvement of drought tolerance is one of the most important subjects in upland rice breeding $^{18}$. NERICAs are expected to exhibit high yield even under conditions where water and fertilizer are limited. Therefore, in a series of experiments, we evaluated the growth and yield performance of NERICAs under rainfed upland conditions with different $\mathrm{N}$ application levels in comparison with improved Japanese cultivars, and tried to identify the traits adaptable to such conditions.

\section{Evaluation of yield performance of NERICAs grown under rain-fed upland and low nitrogen application conditions}

The yield performance of NERICAs (NERICA 1 and NERICA 5) was evaluated in comparison with two Japanese upland rice cultivars, Toyohatamochi and Yumenohatamochi, and a Japanese lowland cultivar Hitomebore. The two NERICAs used in this study were selected from among the progenies as adaptable to the climatic conditions in Sendai $\left(38^{\circ} 16^{\prime} \mathrm{N}\right)$ based on the preliminary tests conducted by other experimental institutes. NERI-
CA 1 and NERICA 5 were among the seven cultivars that were the progeny of an $O$. sativa genotype (WAB56-104) and an $O$. glaberrima genotype $(\mathrm{CG} 14)^{12}$, and released at the first phase of NERICA breeding program. Yumenohatamochi is one of the most drought-tolerant cultivars in $\operatorname{Japan}^{7,18}$. Hitomebore is a Japanese lowland cultivar currently grown dominantly in the Tohoku region, northeastern Japan. Plants were grown under rain-fed upland conditions with two $\mathrm{N}$ application levels (high $\mathrm{N}: 7 \mathrm{~g} \mathrm{~N} \mathrm{~m}^{-2}$ and low $\mathrm{N}: 2 \mathrm{~g} \mathrm{~N} \mathrm{~m}^{-2}$ ). In the high $\mathrm{N}$ plot, mixed fertilizer $\left(\mathrm{N}: \mathrm{P}_{2} \mathrm{O}_{5}: \mathrm{K}_{2} \mathrm{O}=12: 16: 18 \%\right)$ was applied at a rate of $5 \mathrm{~g}$ $\mathrm{N} \mathrm{m}^{-2}$ before transplanting, and ammonium sulfate was added at the panicle formation stage and booting stage at a rate of $1 \mathrm{~g} \mathrm{~N} \mathrm{~m}^{-2}$, respectively. In the low $\mathrm{N}$ plot, the mixed fertilizer was applied at a rate of $2 \mathrm{~g} \mathrm{~N} \mathrm{~m}^{-2}$ and no additional $\mathrm{N}$ was applied. Each cultivar consisted of five rows $6.0 \mathrm{~m}$ long $\left(22.2 \mathrm{hills} \mathrm{m}^{-2}\right)$. Experiments were repeated over two years (2006 and 2007). The plots were irrigated during the first two weeks after transplanting when the soil surface dried to ensure the establishment of seedlings, but not thereafter. The monthly precipitation during experimental periods in Sendai is shown in Table 1. The precipitation in both years was markedly greater than normal in July and October, but substantially lower than normal in August. The soil of the experimental field was classified as fine textured clayey Terrace Yellow soil ( $\mathrm{pH} 6.3$, cation exchange capacity $22.6 \mathrm{cmolc} \mathrm{kg}^{-1}$, total carbon $19.9 \mathrm{~g} \mathrm{~kg}^{-1}$, total nitrogen $1.5 \mathrm{~g} \mathrm{~kg}^{-1}$, and available phosphate (Bray II) $6.7 \mathrm{mg} \mathrm{kg}^{-1}$ ).

The yield of the two NERICAs tended to exceed those of the other cultivars, which was more obvious in the low $\mathrm{N}$ plot, where the NERICAs exhibited greater yield compared with the elite Japanese cultivars (Table 2). Oikeh et al. ${ }^{19}$ examined the effects of four $\mathrm{N}$ levels $(0,3,6$ and $12 \mathrm{~g} \mathrm{~m}^{-2}$ ) on the yield of several NERICA cultivars in a forest agroecosystem in Nigeria, and found that the

Table 1. Monthly precipitation during growth period in 2006 and 2007 in Sendai

\begin{tabular}{lccc}
\hline \hline & \multicolumn{3}{c}{$\begin{array}{c}\text { Precipitation } \\
(\mathrm{mm})\end{array}$} \\
\cline { 2 - 4 } Month & 2006 & 2007 & Normal \\
\hline May & 102 & 114 & 108 \\
June & 155 & 159 & 138 \\
July & 325 & 303 & 160 \\
August & 41 & 135 & 174 \\
September & 215 & 191 & 218 \\
October & 305 & 161 & 99 \\
\hline
\end{tabular}

Normal: Average of 30 years (1971 - 2000). 
yield increased with the increasing $\mathrm{N}$ level. In the present study, the yield of the NERICAs did not respond to the increased $\mathrm{N}$ level. This disagreement between the two studies might be ascribed to differences in soil fertility; the NERICAs in our study absorbed more $\mathrm{N}$ than the amount applied (Table 2), indicating that the soil employed in our study was more fertile than the soil used in Oikeh et al. In addition, Oikeh et al. was conducted in a drought-prone environment; there was a long dry spell for over a month during the mid-growth stage in one of the two years and the soil had poor water-holding capacity (Typic Haplustult). The difference in soil moisture conditions between our study and Oikeh et al. might also be responsible for the different results. The $\mathrm{N}$ uptake was enhanced by high $\mathrm{N}$ application, but the increased $\mathrm{N}$ uptake did not bring about an increase in yield in our study probably because the yield potential of the two NERICAs might have reached its limit under the climatic and cultural conditions. The $\mathrm{N}$ concentration of grain and straw at maturity was higher under a high $\mathrm{N}$ application regime than under a low $\mathrm{N}$ application regime (Table 3). Among the cultivars, the two NERICAs tended to exhibit relatively higher $\mathrm{N}$ concentration under a high $\mathrm{N}$ regime than other cultivars. When grown under a high $\mathrm{N}$ application regime, it appeared that a relatively larger amount of $\mathrm{N}$ remained in the leaf and stem until maturity in both NERICAs, so that the increased $\mathrm{N}$ application did not lead to an increase in yield in these cultivars.

Regarding yield components, the two NERICAs were characterized by having a smaller number of panicles per unit area but a larger number of spikelets per panicle regardless of ecosystem and $\mathrm{N}$ level ${ }^{14}$. The NERICAs maintained the panicle number even under low $\mathrm{N}$ condi- tions, resulting in a larger number of spikelets per area compared with other examined cultivars. The spikelet number per area was most significantly correlated with grain yield among yield components. Thus, the NERICAs exhibited a higher capacity of sink formation under upland and low $\mathrm{N}$ conditions, which appears to be a major trait responsible for greater yielding capacity under such conditions.

Several previous studies examined the yield performance of NERICAs. For example, Futakuchi and Jones ${ }^{6}$ evaluated the growth and yield performance of NERICAs in various growing ecologies (upland, rain-fed lowland,

Table 3. $\mathrm{N}$ concentration of grain and straw of five cultivars grown under different $\mathrm{N}$ application regimes

\begin{tabular}{llll}
\hline \hline \multirow{2}{*}{ Nitrogen } & Cultivar & \multicolumn{2}{c}{ Noncentration (\%) } \\
\cline { 3 - 4 } High & Toyohatamochi & Grain & Straw \\
\cline { 2 - 3 } & Yumenohatamochi & $1.40 \mathrm{a}$ & $0.86 \mathrm{a}$ \\
& Hitomebore & $1.27 \mathrm{ab}$ & $0.81 \mathrm{a}$ \\
& NERICA 1 & $1.43 \mathrm{a}$ & $0.83 \mathrm{a}$ \\
\cline { 3 - 4 } Low & NERICA 5 & $1.27 \mathrm{ab}$ & $0.98 \mathrm{a}$ \\
& Toyohatamochi & $1.28 \mathrm{ab}$ & $0.71 \mathrm{a}$ \\
& Yumenohatamochi & $1.19 \mathrm{ab}$ & $0.67 \mathrm{a}$ \\
& Hitomebore & $1.03 \mathrm{c}$ & $0.68 \mathrm{a}$ \\
& NERICA 1 & $1.29 \mathrm{a}$ & $0.77 \mathrm{a}$ \\
& NERICA 5 & $1.18 \mathrm{~b}$ & $0.74 \mathrm{a}$ \\
\hline
\end{tabular}

Values are shown as the average over the two years (2006 and 2007). Values followed by the same letter in a column within each treatment are not significantly different at $\mathrm{P}<0.05$.

Table 2. Above ground dry weight (DW), grain yield (paddy basis), and nitrogen (N) content of five cultivars grown under different $N$ application regimes for two years (2006 and 2007)

\begin{tabular}{|c|c|c|c|c|c|c|c|}
\hline \multirow[b]{2}{*}{ Nitrogen } & \multirow[b]{2}{*}{ Cultivar } & \multicolumn{3}{|c|}{2006} & \multicolumn{3}{|c|}{2007} \\
\hline & & $\begin{array}{l}\text { DW } \\
\left(\mathrm{g} \mathrm{m}^{-2}\right)\end{array}$ & $\begin{array}{l}\text { Grain yield } \\
\qquad\left(\mathrm{g} \mathrm{m}^{-2}\right)\end{array}$ & $\begin{array}{l}\text { N content } \\
\left(\mathrm{g} \mathrm{m}^{-2}\right)\end{array}$ & $\begin{array}{c}\mathrm{DW} \\
\left(\mathrm{g} \mathrm{m}^{-2}\right)\end{array}$ & $\begin{array}{l}\text { Grain yield } \\
\qquad\left(\mathrm{g} \mathrm{m}^{-2}\right)\end{array}$ & $\begin{array}{l}\text { N content } \\
\left(\mathrm{g} \mathrm{m}^{-2}\right)\end{array}$ \\
\hline \multirow[t]{5}{*}{ High } & Toyohatamochi & $1201 \mathrm{a}$ & $536 \mathrm{ab}$ & $11.3 \mathrm{ab}$ & $976 \mathrm{~b}$ & $509 \mathrm{~b}$ & $12.6 \mathrm{bc}$ \\
\hline & Yumenohatamochi & $1349 \mathrm{a}$ & $667 \mathrm{ab}$ & $12.4 \mathrm{ab}$ & $1307 \mathrm{a}$ & $693 \mathrm{a}$ & $15.3 \mathrm{ab}$ \\
\hline & Hitomebore & $1177 \mathrm{a}$ & $509 \mathrm{~b}$ & $9.9 \mathrm{~b}$ & 997 b & $293 \mathrm{c}$ & $10.7 \mathrm{c}$ \\
\hline & NERICA 1 & $1170 \mathrm{a}$ & $520 \mathrm{~b}$ & $13.6 \mathrm{ab}$ & $1370 \mathrm{a}$ & $715 \mathrm{a}$ & $17.0 \mathrm{a}$ \\
\hline & NERICA 5 & $1502 \mathrm{a}$ & $761 \mathrm{a}$ & $14.6 \mathrm{a}$ & $1491 \mathrm{a}$ & $672 \mathrm{a}$ & $18.1 \mathrm{a}$ \\
\hline \multirow[t]{5}{*}{ Low } & Toyohatamochi & $940 \mathrm{ab}$ & $415 \mathrm{bc}$ & $8.3 \mathrm{~cd}$ & $750 \mathrm{~b}$ & $360 \mathrm{c}$ & $7.9 \mathrm{bc}$ \\
\hline & Yumenohatamochi & $1061 \mathrm{a}$ & $519 \mathrm{ab}$ & $9.7 \mathrm{bc}$ & $941 \mathrm{~b}$ & $524 \mathrm{~b}$ & $9.2 \mathrm{~b}$ \\
\hline & Hitomebore & $671 \mathrm{~b}$ & $253 \mathrm{c}$ & $5.5 \mathrm{~d}$ & $802 \mathrm{~b}$ & $306 \mathrm{c}$ & $6.5 \mathrm{c}$ \\
\hline & NERICA 1 & $1235 \mathrm{a}$ & $565 \mathrm{ab}$ & $13.7 \mathrm{a}$ & $1525 \mathrm{a}$ & $771 \mathrm{a}$ & $14.1 \mathrm{a}$ \\
\hline & NERICA 5 & $1230 \mathrm{a}$ & $643 \mathrm{a}$ & $12.3 \mathrm{ab}$ & $1517 \mathrm{a}$ & 811 a & $14.4 \mathrm{a}$ \\
\hline
\end{tabular}

Values followed by the same letter in a column within each treatment are not significantly different at $\mathrm{P}<0.05$. 
and irrigated lowland), and found better growth and yield performance than their parental $O$. sativa cultivar WAB56-104. Tamamura et al. ${ }^{24}$ compared the yield of NERICAs with that of Japanese upland and lowland cultivars for three years, and found that NERICAs could outyield selected Japanese cultivars under rain-fed upland conditions depending on the year. Our results, which were obtained in a cooler climate, are consistent with these previous results in that the NERICAs exhibited a great yielding ability under rain-fed conditions.

\section{Eco-physiological traits of upland NERICAs responsible for high yield under rain-fed and low $\mathrm{N}$ application conditions}

As described above, the NERICAs were capable of producing higher yield under rain-fed and low $\mathrm{N}$ application conditions. This capability was based on their higher dry matter production and $\mathrm{N}$ uptake; the increment of
DW during ripening period was substantially higher in the NERICAs than in the Japanese cultivars, and the DW increase was significantly correlated with the concurrent $\mathrm{N}$ increment ${ }^{15}$. O'Toole and Baldia ${ }^{21}$ found a close correlation between the amount of $\mathrm{N}$ uptake and the level of cumulative transpiration in rice. Jing et al. ${ }^{9}$ observed a close correlation between the exudation rate and $\mathrm{N}$ uptake. Yamaguchi et al. ${ }^{27}$ found a highly positive correlation between the exudation rate and root respiration during the ripening stage. Consequently, in the following experiments, we focused on the two physiological activities, transpiration and exudation, which are considered to be related to $\mathrm{N}$ uptake. The results showed that the two NERICAs exhibited a higher transpiration rate and exudation rate through the ripening stage regardless of $\mathrm{N}$ application levels compared with the Japanese cultivars (Fig. 1). Figure 2A shows the relationship between the transpiration rate of the flag leaf and $\mathrm{N}$ increment $(\Delta \mathrm{N})$ during the ripening stage. The transpiration rate tended
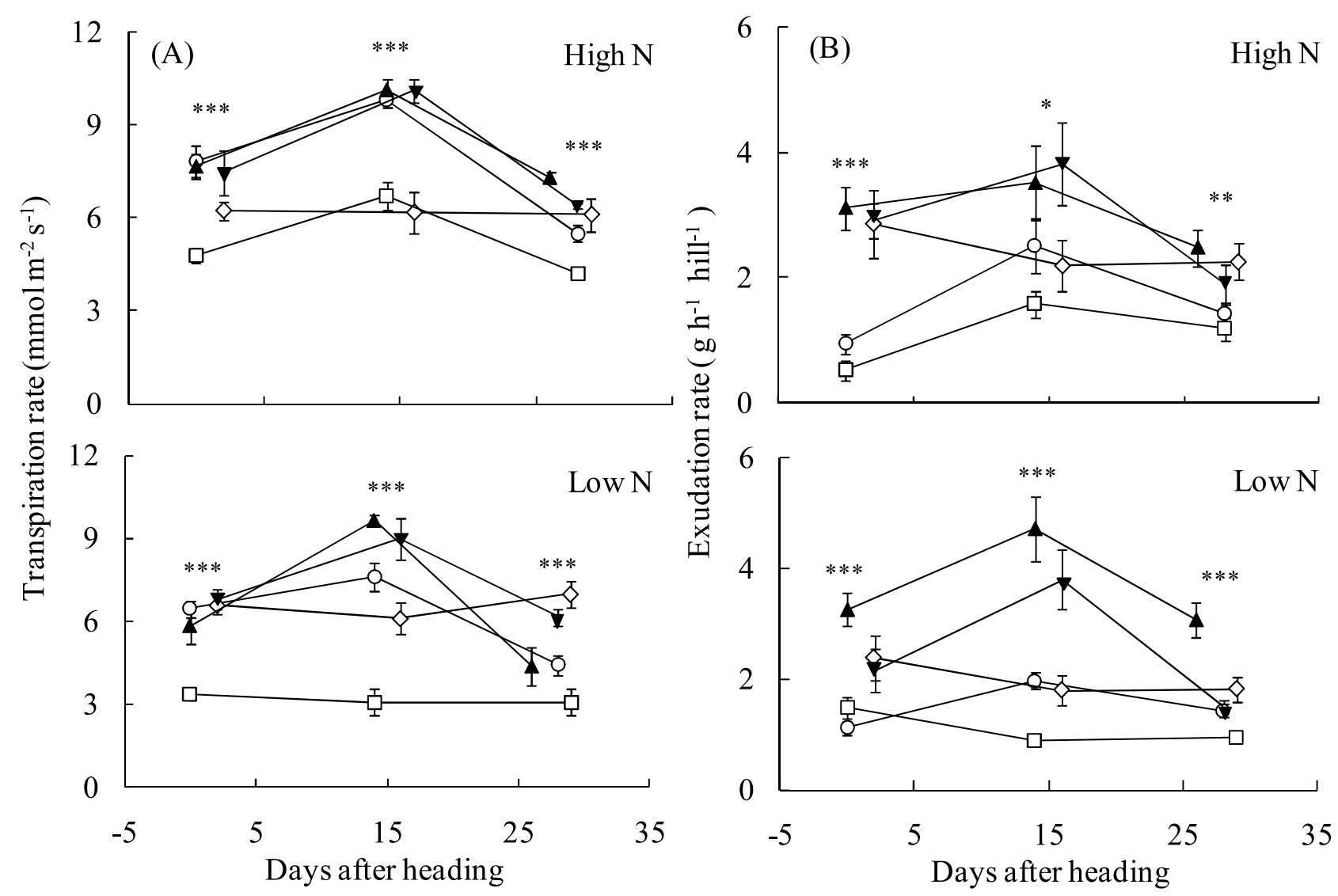

Fig. 1. Changes in the transpiration rate of the flag leaf $(A)$ and exudation rate $(B)$ during the ripening stage in five rice cultivars grown under upland conditions with two $\mathrm{N}$ levels (high and low).

Vertical bars indicate standard errors for measurements on plants sampled from five hills. Levels of significance: * significant at $\mathrm{P}<0.05$, ** significant at $\mathrm{P}<0.01$, *** significant at $\mathrm{P}<0.001$. (Matsunami et al. 2010).

$\longrightarrow$ - Toyohatamochi, $\neg$ : Yumenohatamochi, $\square \square-$ : Hitomebore, $\neg \mathbf{A}$ : NERICA 1,

$\nabla$ : NERICA 5. 
to be correlated with $\Delta \mathrm{N}$, although the correlation was not significant at the $5 \%$ probability level. When the values for Toyohatamochi in the high $\mathrm{N}$ plot are excluded, a significant correlation coefficient $(\mathrm{r}=0.818, \mathrm{P}<0.01)$ was obtained. The exudation rate averaged over the three measurements during the ripening stage was significantly correlated with $\Delta \mathrm{N}$ (Fig. 2B). These results indicated that the upland NERICAs maintained water uptake ability during the ripening stage, and thereby $\mathrm{N}$ absorption that might be accompanied by water uptake, resulting in their greater yielding ability.

In previous studies, NERICAs were found to exhibit higher water use efficiency under conditions of limited soil water availability ${ }^{4,20}$. In our study, the NERICAs exhibited a similar or higher yield under rain-fed conditions compared with Yumenohatamochi, which had been found to possess the greatest drought tolerance among cultivars ever bred in Japan ${ }^{7}$, suggesting that there is still room for further improvement of the drought tolerance of the up- land rice cultivars in Japan. Further elucidation of the physio-morphological traits responsible for the genotypic variation in adaptability to different ecosystems may contribute to a more detailed identification of ideal genotypes that are adaptable to water- and nutrient-limited conditions.

\section{Future research}

In our study, the upland NERICAs were found to possess a greater yield potential compared to elite Japanese upland cultivars. Nonetheless, the present yield level of upland NERICAs in West Africa is lower to the level observed in our study ${ }^{23}$, probably due to the severe environmental conditions in Africa. Therefore, it is critical to further improve tolerance to multiple stresses in rice producing areas in Africa.

The stresses to be addressed include water scarcity, inadequate soil nutrients, and erratic weather. Competi-

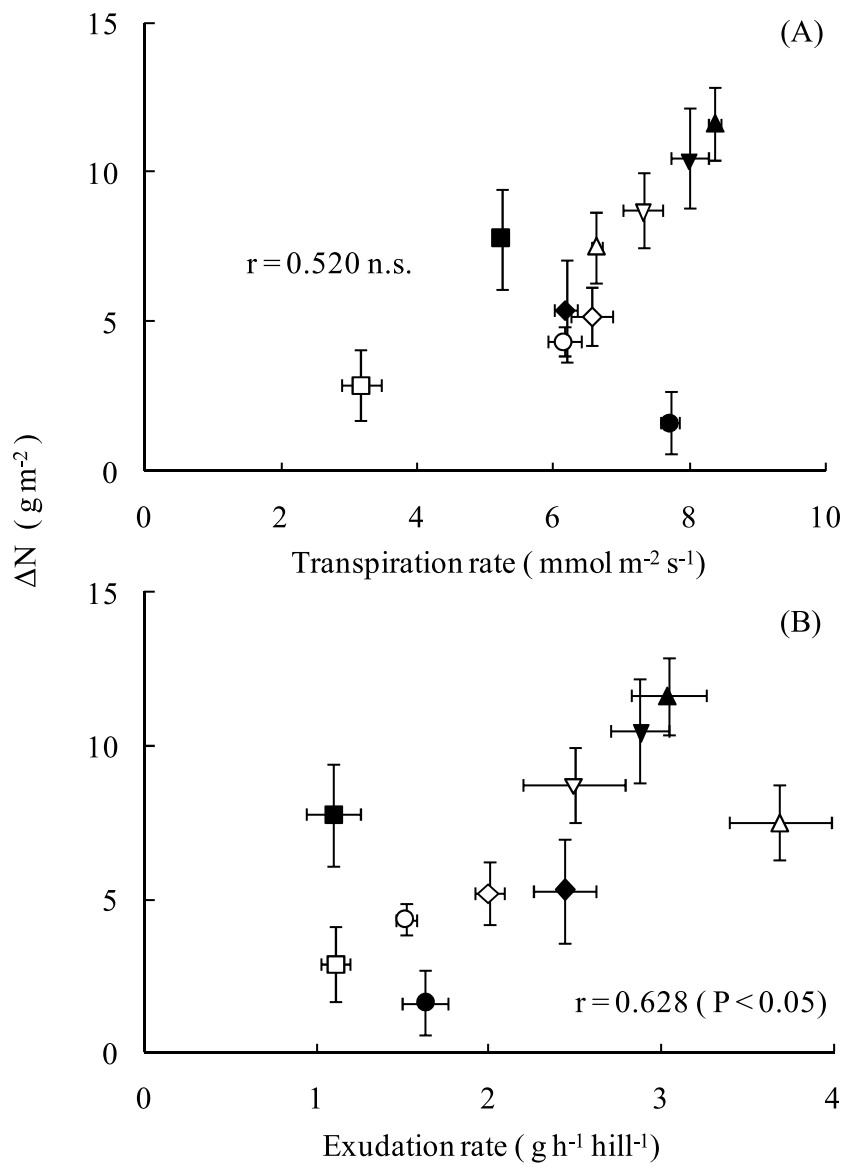

Fig. 2. Relationship between the increment of $N(\Delta N)$ and the transpiration rate of the flag leaf (A) and exudation rate (B) during the ripening period in five rice cultivars grown under upland conditions with two $\mathrm{N}$ levels (high and low).

Values of transpiration rate and exudation rate are the average values of three-time measurements. Vertical bars and horizontal bars indicate standard errors for measurements on plants sampled from five hills. Closed and open symbols indicate high and low N plots, respectively. (Matsunami et al. 2010).

$\bigcirc$ : Toyohatamochi, $\diamond$ : Yumenohatamochi, $\mathbf{\square} \square$ : Hitomebore, $\boldsymbol{\Delta} \triangle$ : NERICA $1, \boldsymbol{\nabla} \nabla:$ NERICA 5. 
tiveness to weeds and resistance to parasitic weeds such as Striga spp., are also critical traits to be addressed ${ }^{22}$.

Research on NERICAs has been directed toward the improvement of rice cultivars adaptable to African environments. However, the constraints on rice production and the strategies to overcome these constraints are largely similar in Africa and Asia. Of these constraints, water scarcity is one of the biggest concerns in many rice-producing areas in Asia. Given that rice consumption is projected to increase in Asia, the enhancement of rice productivity under upland conditions is essential to increase rice production in this region, so that there is a greater necessity to breed new cultivars adaptable to limited water availability. In rice cultivation in Japan, water scarcity is not a serious issue, while reduction in the amount of fertilizer is an important target, because it may mitigate environmental pollution and reduce production costs. Currently, research is being undertaken to promote the multipurpose use of rice grain, and rice genotypes that have high efficiency in $\mathrm{N}$ and water utilization may be used as a genetic resource for that purpose. Thus, the NERICAs may help raise the self-sufficiency ratio of rice in Africa, but the information on the characteristics of NERICAs may be useful for breeding programs in Asia.

\section{Acknowledgments}

We thank Drs. S. Tobita (Japan International Research Center for Agricultural Sciences (JIRCAS)), K. Futakuchi (WARDA), and the staff of the Agricultural Research Institute, Ibaraki Agricultural Center for providing the seeds used in this study.

\section{References}

1. Africa Rice Center (WARDA). Upland NERICA. http:// www.warda.org/warda/uplandnerica.asp.

2. Africa Rice Center (WARDA). Lowland NERICA. http:// www.warda.org/warda/lowlandnerica.asp.

3. Bouman, B.A.M. et al. (2007) Rice and water. Adv. Agron., 92, 187-237.

4. Fujii, M., Miyamoto, Y. \& Ishihara, S. (2006) Studies on drought resistance of Oryza sativa L. and NERICA - Comparison of water use efficiency estimated by pot experiment-. Jpn. J. Crop Sci. 75 (Extra issue 2), 144-145 [In Japanese].

5. Futakuchi, K. (2008) Achievement and outlook in rice research in Africa with special reference to WARDA's activities. In Forefront of rice cultivation in Africa. JIRCAS Working Report No. 57, eds. Sakagami J. \& Ito O., JIRCAS, Tsukuba, Japan, 121-135.

6. Futakuchi, K. \& Jones, M. P. (2005) Yield performance of upland interspecific Oryza sativa $\times$ O. glaberrima progenies under different growing ecologies. Jpn. J. Crop Sci., 74 (Extra issue 2), 34-35 [In Japanese].
7. Hirasawa, H. et al. (1998) Breeding of a new upland rice variety "Yumenohatamochi" with high drought resistance and good eating quality. Breed. Sci., 48, 415-419.

8. Ibaraki Agriculture Institute (2010) http://www.pref. ibaraki.jp/nourin/noucenter/index.html.

9. Jing, J. et al. (2006) Effects of the amount and the kinds of fertilizer on the bleeding rate and nitrogen absorption in Chinese high yielding cultivar, Yangdao 4. Jpn. J. Crop Sci. 75: 249-256 [In Japanese with English summary].

10. Jones, M. P. et al. (1997a) Interspecific Oryza sativa L. $\times O$. glaberrima Steud. Progenies in upland rice improvement. Euphytica, 92, 237-246.

11. Jones, M. P., Mande, S. \& Aluko, K. (1997b) Diversity and potential of Oryza glaberrima Steud. In upland rice breeding. Breed. Sci., 47, 395-398.

12. Kaneda, C. (2006) NERICAs: Their development, dissemination and expectation for African Green Revolution. Jpn. J. Trop. Agr., 50, 293-299 [In Japanese].

13. Maclean, J.L.et al. (2002) Rice Alemanac, third edition. IRRI, WARDA, CIAT, FAO. Manila, Philippines, pp.253.

14. Matsunami, M., Matsunami, T. \& Kokubun, M. (2009) Growth and yield of New Rice for Africa (NERICAs) under different ecosystems and nitrogen levels. Plant Prod. Sci., 12, 381-389.

15. Matsunami, M., Matsunami, T. \& Kokubun, M. (2010) Comparison of nitrogen uptake, transpiration rate and exudation rate between upland NERICAs and Japanese cultivars. Plant Prod. Sci., 13, 347-350.

16. Ministry of Agriculture, Forestry and Fisheries: Preliminary Statistical Report on Agriculture, Forestry and Fisheries. http://www.maff.go.jp/j/tokei/kouhyou/sakumotu/sakkyou_ kome/index.html.

17. Ministry of Foreign Affairs of Japan: TICAD. http://www. mofa.go.jp/mofaj/area/ticad/.

18. Nemoto, N. (2008) Strategies of upland rice breeding in rain fed cultivation. In Forefront of rice cultivation in Africa. JIRCAS Working Report No. 57, eds. Sakagami J. \& Ito O., JIRCAS, Tsukuba, Japan, 55-63.

19. Oikeh, S. O. et al. (2008) Responses of upland NERICA rice to nitrogen and phosphorus in forest agroecosystems. Agron. J., 100. 735-741.

20. Onyango, J. C. et al. (2007) Responses in dry matter production of NERICA to soil moisture stress. Jpn. J. Crop Sci., 76 (Extra issue 1), 168-169.

21. O' Toole, J.C. \& Baldia, E. P. (1982) Water deficits and mineral uptake in rice. Crop Sci., 22, 1144-1150.

22. Parker, C. \& Riches, C.R. (1993) Parasitic weeds of the world: Biology and control. CAB International, Wallingford, UK.

23. Sokei, Y. et al. (2010) Growth and yield performance of upland NERICA varieties in West Africa. Jpn. J. Crop Sci., 79 (Extra issue 2), 2-3.

24. Tamamura, S.et al. (2007) Studies on the yield performance of some new rice for Africa (NERICA) lines, and their related agronomic traits. I. Grain yield of upland and lowland NERICAs. Jpn. J. Crop Sci. 76 (Extra issue 2), 32-33 [In Japanese].

25. Tobita, S. (2002) Rice breeding in West Africa- with special interest in the interspecific hybridization and NERICAs-. Gamma Field Symposia No.41, Institute of Radiation Breeding, NIAR, MAFF. 
26. Tuong, T. P., \& Bouman, B. A. M. (2003) Rice production in water scarce environments. In "Water Productivity in Agriculture: Limits and Opportunities for Improvement" eds. Kijne J. W., Barker R., \& Molden D., CABI Publishing, Wallingford, UK, 53-67.
27. Yamaguchi, T. et al. (1995) Analysis of factors concerning bleeding rate from the basal part of stem in rice plants. Jpn. J. Crop Sci. 64: 703-708 [In Japanese with English summary]. 